\title{
INVESTIGATION OF SALICYLIC ACID-INDUCED CHANGE ON FLAVONOIDS PRODUCTION UNDER CADMIUM TOXICITY IN BUCKWHEAT (FAGOPYRUM ESCULENTUM MOENCH) PLANTS
}

\author{
Yana Kavulych ${ }^{1}$ \\ morkwa_burak@ukr.net
}

Myroslava Kobyletska

kobyletskam@gmail.com

Olga Terek ${ }^{1}$

prof.olga.terek@gmail.com

\author{
${ }^{1}$ Department of Plant Physiology and Ecology \\ Ivan Franko National University of Lviv \\ 4 Hrushevskoho str., Lviv, Ukraine, 79005
}

\begin{abstract}
Salicylic acid (SA) is an imperative endogenous plant hormone. It is considered as one of the most important signaling molecule, involved in both abiotic and biotic stress tolerance. Application of optimal concentrations $(0,05 \mathrm{mM})$ of SA enhances plants tolerance to cadmium stress by modulating levels of several metabolites, including components of antioxidative defense, osmolytes, secondary metabolites, and metal-chelating compounds. We showed that when SA and Cd were applied simultaneously, the damage was less pronounced than without SA. SA treatment itself also caused the oxidative stress, but decreased flavonoids content, regulated phenolic synthesis and lignin formation. Thus, the main purpose was to investigate how SA treatment, used prior the $\mathrm{Cd}$ stress, prevented the damaging heavy metal effects in buckwheat plants. And show that regulation of flavonoids and lignin formation are an important indicator of stability and stress resistance. The obtained data will expand the knowledge about the role of phenolic compounds and the action of salicylate under the cadmium chloride conditions. Also data with this type of buckwheat - Fagopyrum esculentum Moench, Rubra variety under the action of cadmium chloride and salicylic acid not found.

Keywords: buckwheat - Rubra variety, flavonoids production, lignin formation, salicylic acid, cadmium chloride.
\end{abstract}

DOI: $10.21303 / 2504-5695.2019 .00986$

\section{Introduction}

Salicylic acid (SA) may act as a component of the signal transduction system; it has promoting effects on various physiological processes, related to plant growth and development [1, 2]. As a phenolic compound it is important in defense against pathogen attack [3], certain abiotic stresses, in particular, heat and heavy metals stress. Heavy metal contamination issues are becoming of increase in Ukraine and worldwide, with many documented cases of metal toxicity in mining industries areas, foundries, smelters, coal-burning power plants and agriculture. The heavy metal accumulation in soils is of concern in agricultural production due to the adverse effects on food safety and marketability, crop yields and environmental health of soil organisms. Cd is one of the most aggressive heavy metals that induce oxidative stress in plants [4]. Cadmium has a high impact on plants and consequently it affects an ecosystem, where plants form an integral component.

Salicylic acid (SA) is an imperative endogenous plant hormone. It is considered as one of the most important signaling molecule, involved in both abiotic and biotic stress tolerance. Application of optimal concentrations $(0.05 \mathrm{mM})$ of SA enhances plants tolerance to the cadmium stress by modulating levels of metabolites, including components of secondary metabolites.

Flavonoids, the important secondary metabolites with many and diverse key functions that belong to a largest class of substances, produced by plants - phenylpropanoids. These substances are of interest of plant and animal biochemists, plant pathologists, geneticists and biotechnologists. 
They are involved in major processes, such as cell wall formation, photosynthesis, respiration, allelopathic interactions between plants, protection against pathogens and herbivores [5]. They are produced by plants in response to biotic or abiotic stresses, such as wounding, UV-radiation, exposure to pollutants, ozone, and other adverse environmental conditions [6, 7]. It was reported, that $0.05 \mathrm{mM}$ exogenous SA before the reproductive stage resulted in a higher seed germination.

Buckwheat (Fagopyrum esculentum Moench) belongs to crops of secondary importance in many countries. The main producers are China, Ukraine, Kazakhstan and Russian Federation, but generally it is consumed or traded locally. Except for the wide spread of this variety, Rubra variety - Fagopyrum esculentum Moench., characterized a high initial content of phenolic compounds, and can be investigated the effect of salicylate and cadmium, as well as changes under these conditions.

The aim of the present study was to investigate the effect of SA on cadmium stress in buckwheat, changes of flavonoids contents, lignin formation, which will allow to see external (lignification) and internal (flavonoid formation) under stress conditions. Because the lignification and formation of flavonoids are an important process in the chelation of heavy metals and their retention in the compartments of the plant cell.

\section{Materials and Methods}

Buckwheat (Fagopyrum esculentum Moench.) Rubra variety was used in the laboratory experiments. Growing conditions: $16 \mathrm{~h}$ - photoperiod, $15{ }^{\circ} \mathrm{C}$ - night temperature, $20{ }^{\circ} \mathrm{C}-$ day temperature. Previously sterilized seeds were soaked for $5 \mathrm{~h}$ (experimentally selected for buckwheat) in the $0.05 \mathrm{mM} \mathrm{SA}$ solution (experiment) and distilled water (control). Then seeds were germinated on a filter paper in Petri dishes at $23 \pm 1{ }^{\circ} \mathrm{C}$ for three days. Uniform seedlings were transferred to pots, filled with $1.5 \mathrm{~kg}$ washed and inciderated sand, artificially contaminated with $\mathrm{Cd}$ as $\mathrm{CdCl}_{2} \cdot 2.5 \mathrm{H}_{2} 0$ at levels of 0 and $25 \mathrm{mg} \mathrm{Cd} \mathrm{kg} \mathrm{sand.} \mathrm{The} \mathrm{pots} \mathrm{were} \mathrm{watered} \mathrm{to} 60 \%$ water holding capacity of the sand and fertilized twice a week with $25 \mathrm{ml}$ modified Hoagland's nutrient solution. The concentrations of flavonoids and lignin were determined in shoots on the $14^{\text {th }}$ and $21^{\text {st }}$ days of plant growth. The experimental plants were in the phase of the second (14 days) or the third leaf (21 days).

\section{1. Flavonoids estimation}

The plant material was fixed at $105^{\circ} \mathrm{C}$ for $15 \mathrm{~min}$ and dried at $40{ }^{\circ} \mathrm{C}$ for dry matter obtaining. Dry samples (50-100 mg) were homogenized with a $0.2 \mathrm{~g}$ glass powder and transferred to the testtube with $2 \mathrm{ml}$ methanol for 1 hour for extraction. Then, the mixture was centrifuged at $3000 \mathrm{~g}$ for $5 \mathrm{~min}$. The supernatant was used for the next steps of flavonoids analysis. Series of standard solutions of rutin and quercetin (concentrations $0.5,1,2,4 \mathrm{mg} / \mathrm{ml}$ ) and $0.5 \mu \mathrm{l}$ of the extract were dropped on a chromatography thin plate with silicagel Sorbfil (Ukraine). The solvent system for the separation of flavonoid compounds was ethyl acetate - acetonitrile $-35 \%$ formic acid (13:5:2, v/v). Visualization was performed by sprinkling with a $0.1 \% \mathrm{TiOSO}_{4}$, chromatograms were analyzed at wavelength $450 \mathrm{~nm}$ with spectrophotometer ULAB 101 (China) [8].

\section{2. Lignin determination}

We used the Wiesner's reaction, based on phloroglucinol condensation with cinnamic aldehydes (coniferyl aldehyde) in the acidic environment and formation of cherry red product [9]. A thin stem sections after washing in the distilled water were placed on a glass slide and stained by $5 \%$ alcohol solution of phloroglucine, followed by $25 \% \mathrm{H}_{2} \mathrm{SO}_{4}$ as described in [10]. After 10 mins, the sections were viewed into a microscope. The aperture in each variant of the lignin test was measured, using a program Image Tool (USA).

\section{3. Statistical analysis}

Each experiment was performed in five replications. The means and standard deviations were calculated by the JMP Pro 14 and Microsoft Office Excel 11. Statistical significance of difference was evaluated with Student's t-test $(P<0.05)$. 


\section{Results and Discussion}

SA plays a crucial role in the regulation of physiological and biochemical processes during the plants entire lifespan. It is known that the content of endogenous SA can be increased by exogenous applications [11]. In our experiments exogenous $0.05 \mathrm{mM} \mathrm{SA}$ in dosage $10 \mathrm{ml}$ per g of seeds influenced a seed germination rate (Table 1).

Table 1

Effect of $0.05 \mathrm{mM} \mathrm{SA}$ on the germination of buckwheat seeds Rubra variety in the laboratory conditions, Petri dishes, $20.0 \pm 1.0^{\circ} \mathrm{C}$

\begin{tabular}{ccccc}
\hline \multirow{2}{*}{ Variants } & \multicolumn{3}{c}{ Germination rate, $\%$} & Percent of germination, \% \\
\cline { 2 - 4 } & First day & Second day & Third day & $92.0 \pm 3.0$ \\
Control $\left(\mathrm{H}_{2} \mathrm{O}\right)$ & $78.0 \pm 3.0$ & $87.0 \pm 6.0$ & $91.0 \pm 3.0$ & $92.0 \pm 3.0$
\end{tabular}

Exogenous SA also promoted root growth on the initial stages, compared with the control treatment (Fig. 1).

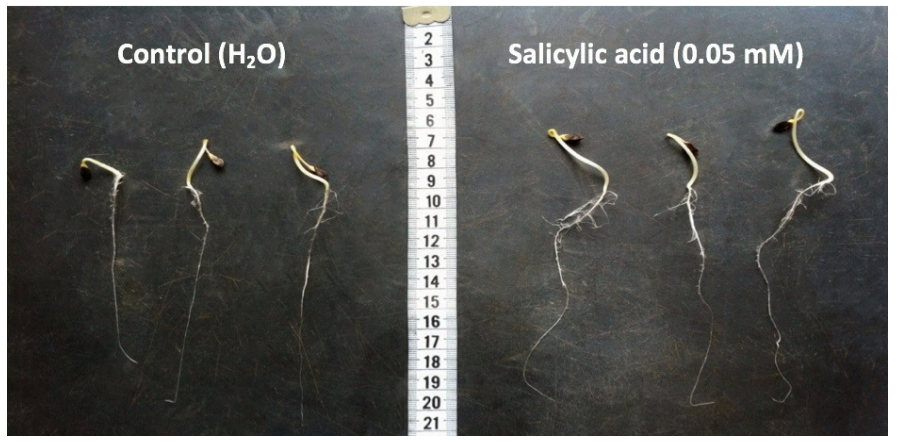

Fig. 1. The effect of the SA $(0.05 \mathrm{mM})$ on early growth of buckwheat Rubra var. plants ( $7^{\text {th }}$ day of germination, Petri dishes)

The endogenous SA content could be increased exogenously and this action can induce plant stress [12].

Any biotic and abiotic stress effects can intensify the biosynthesis of flavonoids in different anatomical parts of the plant [15]. A plant cell wall is the first barrier against external hazards, one of the general reactions of plants under biotic and abiotic stresses is the accumulation of reactive oxygen species, accompanied by an increase in lignin accumulation [16-18]. Flavonoids possess antioxidant properties and realize a protective effect and barrier function due to the formation of lignin [13].

The result of our investigation showed that flavonoids level was higher in buckwheat shoots (Fig. 2, 3). Under the SA treatment an increase of the flavonoids content on a $14^{\text {th }}$ and $21^{\text {st }}$ days of experiment was observed. Cadmium $(25 \mathrm{mg} / \mathrm{kg})$ induced a slight increase in flavonoids concentration, compared to the control (Fig. 3). Under the combined action of SA and cadmium on $21^{\text {st }}$ day of experiment a nearly 3 -fold decrease in flavonoids was observed (Fig. 2).

The results obtained are confirmed by literature data for minor changes in the flavonoids pool due to the cadmium stress, which may indicate their conversion to coumarins or lignin $[13,14]$.

In the roots we observed a slight increase in flavonoids (Fig. 3). On 14-day of growth with SA it could be caused by changes in common synthetic phenylpropanoid pathways. Cadmium led to $8 \%$ decrease of flavonoids concentration in the roots on 14-days plants, and its 3 -fold increase on 21 days (Fig. 3). However, in the shoots it did not change during the experiment (Fig. 2).

Lignin biosynthesis is also closely related to plant heavy metals absorption, transport and tolerance. It is reported, that lignification of xylem in roots and shoots can reduce the transport of Cd to the grain [19]. 


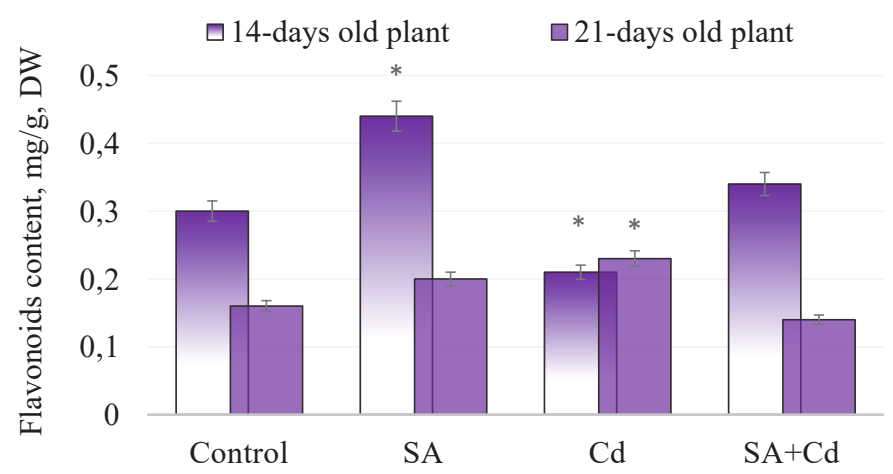

Fig. 2. The $\mathrm{SA}(0.05 \mathrm{mM})$ and $\mathrm{CdCl}_{2}(25 \mathrm{mg} / \mathrm{kg})$ effects on flavonoids content in a shoots of 14- and 21-days buckwheat (Fagopyrum esculentum Moench, Rubra var.) plants; ${ }^{*}-P<0.05$

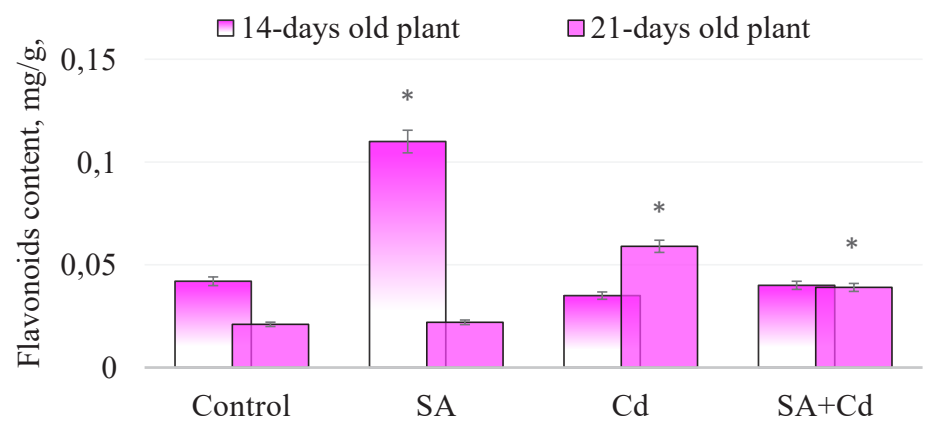

Fig. 3. The $\mathrm{SA}$ and $\mathrm{CdCl}_{2}$ effect on flavonoids content in roots of 14 and 21-days buckwheat (Fagopyrum esculentum Moench, Rubra var.) plants; *-P<0.05

Our results show the differences in lignin accumulation in the shoots under the SA and Cd influence. It should be noted, that for the detection of lignin there were selected different parts of the plant - leaf, stem, node. Lignin formation was not noticed in the control condition, no in the longitudinal (Fig. 4) or in the cross sections (Fig. 5) of the shoots.

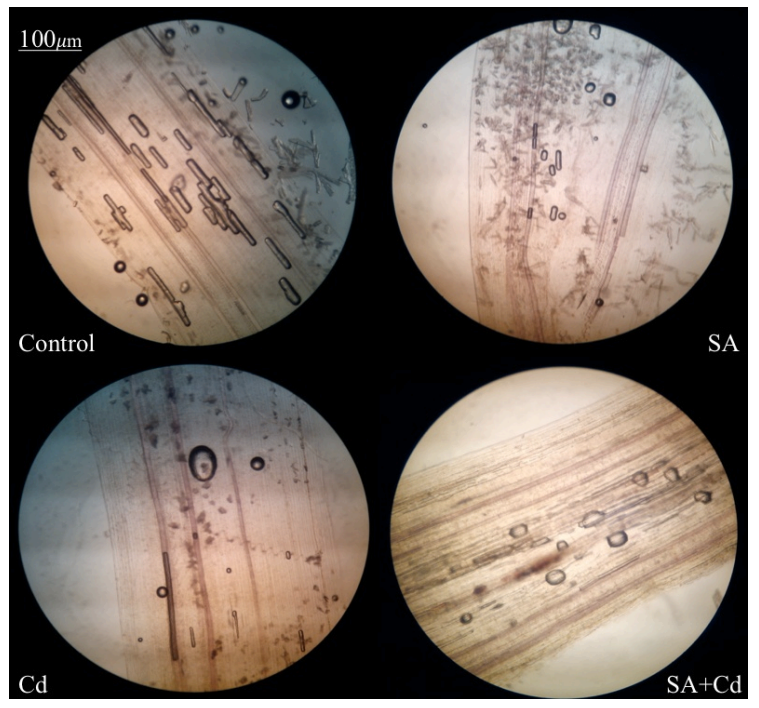

Fig. 4. Localization of lignin (longitudinal section) in a shoots of buckwheat (Fagopyrum esculentum Moench, Rubra var.) plants under the action of cadmium chloride and salicylic acid

It was shown, that different parts of plants have different content and distribution of lignin. The stem node had a significantly higher density than the internode. The reason for this may be the 
high content of phenolic acids [13]. We assume SA as a substance of phenolic origin that also had an influence on the process of lignification in buckwheat plants, the similar results were obtained on mutants and transgenic plants and they proved the metabolic plasticity of lignin biosynthesis (Fig. 4, 5).

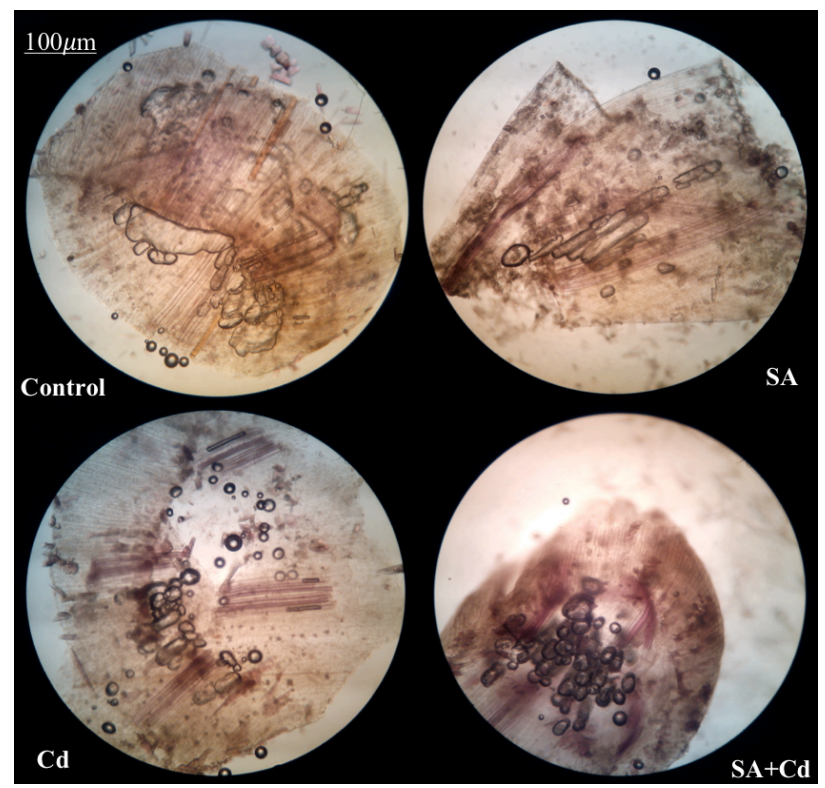

Fig. 5. Localization of lignin (cross section) in a shoots of buckwheat (Fagopyrum esculentum Moench, Rubra var.) plants under the action of cadmium chloride and salicylic acid

\section{Conclusions}

We can assume that SA in concentration 0,05 $\mathrm{mM}$ has the positive effect on seed germination. Pre-soaking with this concentration had more beneficial effect on the plant than the treatment with distilled water. SA treatments revealed a stimulative effect on flavonoids accumulation in buckwheat plants. The obtained results indicate that lignin formation correlated with flavonoids content. Moreover, cadmium and SA acid increase lignin formation, but without any change in flavonoids content. But, when the SA treatment used prior the Cd stress, it prevented the damaging heavy metal effect.The treatment with salicylic acid can regulate the content of phenolic compounds, which in turn leads to chelation of metals and prevents entry into the stem or grain of the plant. Our results can be implemented in agronomy and horticulture of cereal plants.

\section{References}

[1] He, Y. L., Liu, Y. L., Chen, Q., Bian, A. H. (2002). Thermotolerance related to antioxidation induced by salicylic acid and heat hardening in tall fescue seedlings. J. Plant Physiol. Mol. Biol., 28, 89-95.

[2] Noreen, S., Ashraf, M., Hussain, M., Jamil, A (2009). Exogenous application of salicylic acid enhances antioxidative capacity in salt-stressed sunflower (Helianthus annuus L.) plants. Pakistan Journal of Botany, 41 (1), 473-479.

[3] Raskin, I. (1992). Role of Salicylic Acid in Plants. Annual Review of Plant Physiology and Plant Molecular Biology, 43 (1), 439-463. doi: https://doi.org/10.1146/annurev.pp.43.060192.002255

[4] Hegedüs, A., Erdei, S., Horváth, G. (2001). Comparative studies of H2O2 detoxifying enzymes in green and greening barley seedlings under cadmium stress. Plant Science, 160 (6), 1085-1093. doi: https://doi.org/10.1016/s0168-9452(01)00330-2

[5] Douglas, C. J. (1996). Phenylpropanoid metabolism and lignin biosynthesis: from weeds to trees. Trends in Plant Science, 1 (6), 171-178. doi: https://doi.org/10.1016/1360-1385(96)10019-4

[6] Dixon, R. A., Paiva, N. L. (1995). Stress-Induced Phenylpropanoid Metabolism. The Plant Cell, 7 (7), 1085. doi: https://doi.org/ $10.2307 / 3870059$

[7] Lavola, A., Aphalo, P. J., Lahti, M., Julkunen-Tiitto, R. (2003). Nutrient availability and the effect of increasing UV-B radiation on secondary plant compounds in Scots pine. Environmental and Experimental Botany, 49 (1), 49-60. doi: https://doi.org/ $10.1016 / \mathrm{s} 0098-8472(02) 00057-6$ 
[8] Smirnov, O., Kosyan, A., Kosyk, O. (2012). The Cycocel effect on flavonoids content and phenylalanine ammonia-lyase (PAL) activity in buckwheat (Fagopyrum esculentum Moench.) plant. Studia Biologica, 6 (3), 247-252. doi: https://doi.org/10.30970/ sbi.0603.230

[9] Wiesner, J. (1878). Note über das Verhalten des Phloroglucins und einiger verwandter Körper zur verholzten Zellmembran. Sitzungsberichte der Akademie der Wissenschaften mathematisch-naturwissenschaftliche Klasse, 77, 60-66.

[10] Ovrutska, I. I. (2007). Conceptions of the lignification of cells walls. Ukrainian Botanical Journal, 64 (5), 720-729. Available at: http://dspace.nbuv.gov.ua/handle/123456789/3780

[11] Liljegren, S. J., Ditta, G. S., Eshed, Y., Savidge, B., Bowman, J. L., Yanofsky, M. F. (2000). SHATTERPROOF MADS-box genes control seed dispersal in Arabidopsis. Nature, 404 (6779), 766-770. doi: https://doi.org/10.1038/35008089

[12] Molodchenkova O. (2001). Estimated functions of salicylic acid in plants. Physiology and biochemistry cult. plants, 33 (6), 463-473.

[13] Hatfield, R., Vermerris, W. (2001). Lignin Formation in Plants. The Dilemma of Linkage Specificity. Plant Physiology, 126 (4), 1351-1357. doi: https://doi.org/10.1104/pp.126.4.1351

[14] Michalak, A. (2006). Phenolic compounds and their antioxidant activity in plants growing under heavy metal stress. Polish J. of Environ. Stud., 15 (4), 523-530. Available at: https://pdfs.semanticscholar.org/f45a/ed04dedbf29960a2bdcaf2a1b025b235c0f6.pdf

[15] Kalachova, T. A., Yakovenko, O. M., Kravets, V. S. (2013). Regulation of phenolic antioxidants level in soybean tissues under the salicylic acid action. Proceedings of the International Interdisciplinary Scientific Conference "Biologically Active Substances and Materials: Fundamental and Applied Issues of Preparation and Application”. Kyiv.

[16] Liu, Q., Luo, L., Zheng, L. (2018). Lignins: Biosynthesis and Biological Functions in Plants. International Journal of Molecular Sciences, 19 (2), 335. doi: https://doi.org/10.3390/ijms19020335

[17] Moura, J. C. M. S., Bonine, C. A. V., de Oliveira Fernandes Viana, J., Dornelas, M. C., Mazzafera, P. (2010). Abiotic and Biotic Stresses and Changes in the Lignin Content and Composition in Plants. Journal of Integrative Plant Biology, 52 (4), $360-376$. doi: https://doi.org/10.1111/j.1744-7909.2010.00892.x

[18] Schutzendubel, A. (2002). Plant responses to abiotic stresses: heavy metal-induced oxidative stress and protection by mycorrhization. Journal of Experimental Botany, 53 (372), 1351-1365. doi: https://doi.org/10.1093/jexbot/53.372.1351

[19] Ahsan, N., Nakamura, T., Komatsu, S. (2010). Differential responses of microsomal proteins and metabolites in two contrasting cadmium (Cd)-accumulating soybean cultivars under Cd stress. Amino Acids, 42 (1), 317-327. doi: https://doi.org/10.1007/ s00726-010-0809-7 